\title{
Prediction of Prognosis of Intermediate-Stage HCC Patients: Validation of the Tumor Marker Score in a Nationwide Database in Japan
}

\author{
Atsushi Hiraoka ${ }^{a}$ Kojiro Michitaka ${ }^{a}$ Takashi Kumada $^{b}$

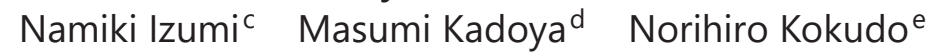 \\ Shoji Kubo ${ }^{f}$ Yutaka Matsuyamag Osamu Nakashimah

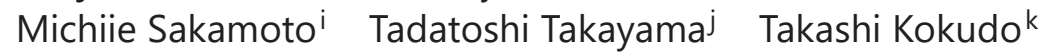 \\ Kosuke Kashiwabaral Susumu Eguchi ${ }^{m}$ Tatsuya Yamashita ${ }^{n}$ \\ Masatoshi Kudo ${ }^{\circ}$ The Liver Cancer Study Group of Japan \\ ${ }^{a}$ Gastroenterology Center, Ehime Prefectural Central Hospital, Matsuyama, Japan;

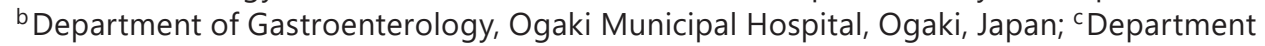 \\ of Gastroenterology, Musashino Red Cross Hospital, Tokyo, Japan; dDepartment of \\ Radiology, Shinshu University School of Medicine, Matsumoto, Japan; e National Center \\ for Global Health and Medicine, Tokyo, Japan; ${ }^{f}$ Department of Hepato-Biliary-Pancreatic \\ Surgery, Osaka City University Graduate School of Medicine, Osaka, Japan; ${ }^{9}$ Department \\ of Biostatistics, School of Public Health, University of Tokyo, Tokyo, Japan; ${ }^{\text {h}}$ Department \\ of Clinical Laboratory Medicine, Kurume University Hospital, Kurume, Japan; 'Department \\ of Pathology, Keio University School of Medicine, Tokyo, Japan; jDepartment of Digestive \\ Surgery, Nihon University School of Medicine, Tokyo, Japan; ${ }^{k}$ Hepato-Biliary-Pancreatic \\ Surgery Division, Department of Surgery, Graduate School of Medicine, University of \\ Tokyo, Tokyo, Japan; 'Department of Biostatistics, School of Public Health, Graduate \\ School of Medicine, The University of Tokyo, Tokyo, Japan; mDepartment of Surgery, \\ Nagasaki University Graduate School of Biomedical Sciences, Nagasaki, Japan; ${ }^{\text {n} A d v a n c e d ~}$ \\ Preventive Medical Research Center, Kanazawa University, Kanazawa, Japan; ${ }^{\circ}$ Department \\ of Gastroenterology and Hepatology, Kindai University School of Medicine, Osaka, Japan
}

\section{Keywords}

Hepatocellular carcinoma - BCLC-B - TACE-refractory status - Alpha-fetoprotein · Fucosylated alpha-fetoprotein · Des-gamma-carboxy prothrombin · Prognosis

\section{Abstract}

Background/Aim: Adequate assessment of transcatheter arterial chemoembolization (TACE)refractory status has become more important for switching treatment in intermediate-stage (BCLC-B) hepatocellular carcinoma (HCC) patients treated with TACE. The usefulness of a previously proposed tumor marker score for predicting prognosis of BCLC-B HCC patients treated with TACE was investigated. Methods: Using a nationwide database, we examined the re- 
cords of 1,306 naïve BCLC-B HCC with Child-Pugh A who were treated from 2001 to 2007, after excluding those with missing data (hepatic function or tumor markers) or cases with a single large tumor. Alpha-fetoprotein (AFP) $\geq 100 \mathrm{ng} / \mathrm{mL}$, fucosylated AFP (AFP-L3) $\geq 10 \%$, and des-gamma-carboxy prothrombin $\geq 100 \mathrm{mAU} / \mathrm{mL}$ were markers used to define positive cases. The number of positive tumor markers was used as a prognostic score, and its predictive value was evaluated in a retrospective manner. Results: Median survival time became shorter along with increased score $(0,1, \geq 2=4.8,3.8,3.2$ years, respectively; $p<0.01)$. Tumor marker score ( $\geq 2$; hazard ratio $[H R] 1.675,95 \%$ confidence interval $[\mathrm{Cl}] 1.372-2.044, p<0.001$ ), serum levels of albumin ( $\geq 3.5 \mathrm{~g} / \mathrm{dL} ; \mathrm{HR} 0.726,95 \% \mathrm{Cl} 0.528-0.997, p=0.048)$, and up-to-7 criteria (HR $1.673,95 \% \mathrm{Cl} 1.400-2.000, p<0.001$ ) were significant prognostic factors for death in the Cox hazard multivariate analysis. Conclusion: Tumor marker score had a useful predictive prognostic value in BCLC-B HCC treated with TACE. Especially in patients with a tumor marker score of 2 or greater, a poor therapeutic response should be expected, and appropriate judgement of TACE-refractory status is necessary.

(c) 2019 S. Karger AG, Basel

\section{Introduction}

During the clinical course of hepatocellular carcinoma (HCC), many patients show frequent recurrence following curative treatment and finally reach an out-of-indication status for curative therapy. For intermediate-stage (BCLC-B) HCC patients [1, 2], transcatheter arterial chemoembolization (TACE) is recommended as standard therapy [3]. Recently, the concept of switching to a tyrosine kinase inhibitor (TKI), a new therapeutic option for advanced-stage HCC, has been proposed for TACE-refractory patients [4,5]. The prognosis of patients receiving TKI treatment is dependent on hepatic reserve function. In a previous study, we reported that repeated TACE gradually reduces hepatic reserve function [6]. Thus, appropriate judgment of TACE refractory status has become important to avoid not only lower effective but also harmful TACE, especially in BCLC-B patients expected for poor prognosis.

Alpha-fetoprotein (AFP),fucosylatedAFP(AFP-L3), and des-gamma-carboxyprothrombin (DCP) are used as tumor markers for HCC in Japan. However, elevated levels and response to TACE vary among them. Although the Liver Cancer Study Group of Japan (LCSGJ) criteria include "continuous elevation of tumor markers right after TACE even though transient minor reduction is observed" as one of the signs of TACE failure/refractory status [5, 7], few reports have presented definitive tumor marker levels that can be regarded as significant elevation for more detailed TACE refractory prediction. Recently, a tumor marker score that uses AFP, AFP-L3, and DCP was proposed for predicting prognosis of patients with BCLC-B HCC undergoing TACE treatment [8-10]. In this validation study, we analyzed the usefulness of this tumor marker score as a prognostic factor by examining nationwide database records of BCLC-B and Child-Pugh class A patients who received TACE.

\section{Materials and Methods}

Patients

We obtained details regarding 64,928 patients with naïve HCC in Japan recorded from January 2001 to December 2007 by examining a nationwide survey system. Inclusion criteria were set as follows: (i) BCLC-B patients who were treated with TACE, (ii) those with tumor marker data (AFP, AFP-L3, and DCP), and (iii) those with Child-Pugh A, while exclusion criteria were as follows: (i) lack of information on tumor burden (size, number, vascular invasion, or extrahepatic metastasis), (ii) BCLC-B patients who were not treated with 


\section{Liver Cancer}

\begin{tabular}{l|l}
\hline Liver Cancer 2019;8:403-411 \\
\hline DOI: 10.1159/000495944 & $\begin{array}{l}\text { @) 2019 S. Karger AG, Basel } \\
\text { www.karger.com/lic }\end{array}$ \\
\hline
\end{tabular}

Hiraoka et al.: Tumor Marker Score in Patients Undergoing TACE

Fig. 1. Flow diagram of the patients who were enrolled in the present analysis. Some patients (*) had overlapping lack of data on tumor markers.

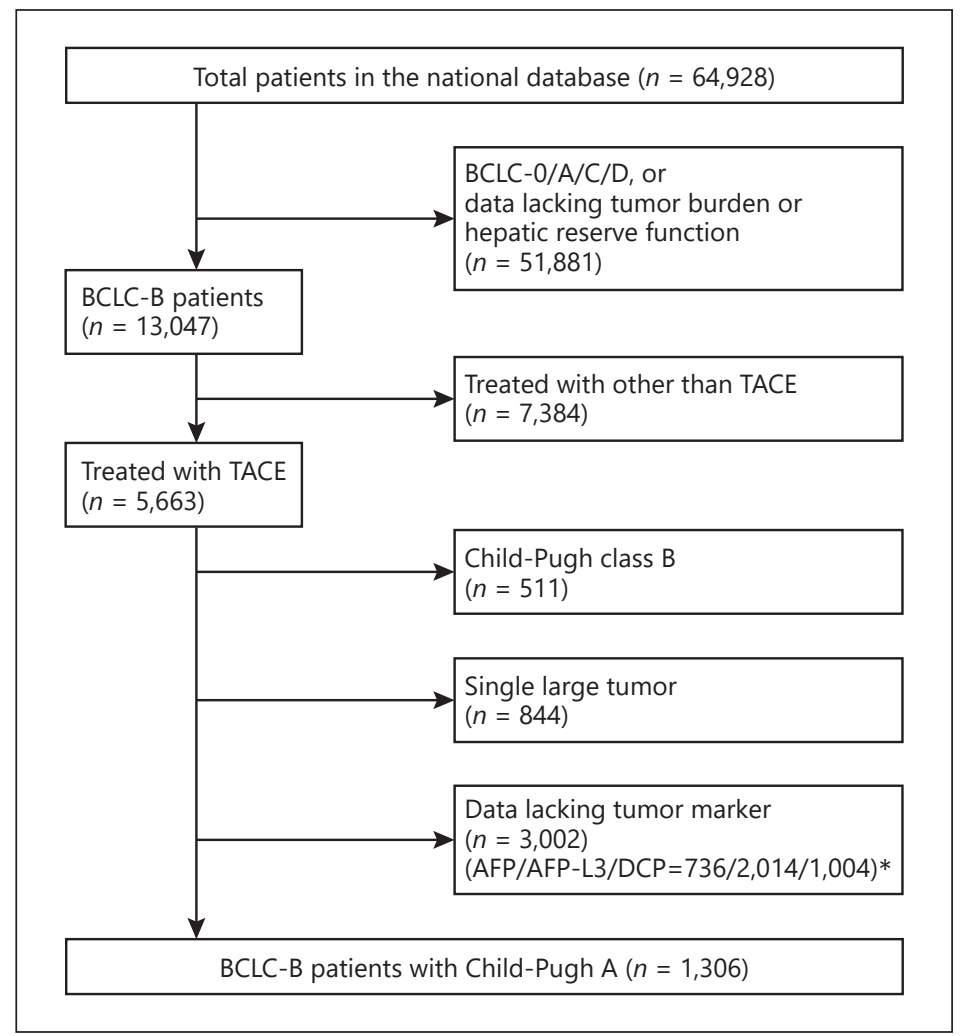

TACE, (iii) lack of data of tumor markers or hepatic reserve function (albumin, total-bilirubin, prothrombin time, ascites information, or hepatic coma), (iv) those with Child-Pugh B, and (v) single large tumor $(>5 \mathrm{~cm})$ because it remains controversial whether those should be classified as intermediate stage. There were 3,002 BCLC-B patients with Child-Pugh A, who had overlapping lack of data of tumor markers (AFP/AFP-L3/ DCP $=736 / 2014 / 1004)$. Finally, the records of 1,306 BCLC-B patients with Child-Pugh class A were subjected to analysis (Fig. 1).

In the patients who were positive for the anti-hepatitis $\mathrm{C}$ virus (HCV) or hepatitis B surface antigen (HBsAg), HCC was considered to be due to those, while patients negative for both anti-HCV and HBsAg were judged as nonviral (NBNC) HCC.

\section{Tumor Marker Score}

Positivity for AFP was defined as $\geq 100 \mathrm{ng} / \mathrm{mL}$, while that for AFP-L3 was $\geq 10 \%$ and for DCP was $\geq 100$ $\mathrm{mAU} / \mathrm{mL}$. We added up the number of positive tumor markers to determine the prognostic score, noted as 0,1 , or $\geq 2$ [8-10], and evaluated the predictive value of that score for prognosis in a retrospective manner. Tumor node metastasis stage presented by the Liver Cancer Study Group of Japan (LCSGJ) 6th edition was used for staging [11].

Using the reported Bolondi [2] and Kinki criteria [12], patients were classified according to Child-Pugh score and tumor burden (Milan criteria [13], up-to-7 criteria [14]). All were divided into B1 and B2 subclasses, which is common when using the Bolondi and Kinki criteria, because each of the present patients was classified as Child-Pugh A (score of 5 or 6 ).

\section{Statistical Analysis}

The Kruskal-Wallis test, one-way ANOVA, and a log-rank test with the Kaplan-Meier method were used where appropriate. Hazard ratio (HR) for death related to each clinical factor was evaluated using Cox hazard analysis. For multiple comparisons, Holm's method was used. All statistical analyses were performed using Easy R (EZR), version 1.29 (Saitama Medical Center, Jichi Medical University, Saitama, Japan) [15], a graphical user interface for the R Statistical Computing Environment (R Foundation, Vienna, Austria). All $p$ values were derived from two-tailed tests, with $p<0.05$ accepted as statistically significant. 
Table 1. Characteristics of intermediate-stage patients classified as Child-Pugh class A

\begin{tabular}{|c|c|c|c|c|c|}
\hline & $\begin{array}{l}\text { Total } \\
(n=1,306)\end{array}$ & $\begin{array}{l}\text { Tumor marker } \\
\text { score } 0 \\
(n=296)\end{array}$ & $\begin{array}{l}\text { Tumor marker } \\
\text { score } 1 \\
(n=434)\end{array}$ & $\begin{array}{l}\text { Tumor marker } \\
\text { score } \geq 2 \\
(n=576)\end{array}$ & $p$ value \\
\hline Age, years ${ }^{a}$ & $69.4(9.0)$ & $69.4(8.7)$ & $69.3(8.5)$ & $69.5(9.5)$ & $0.982^{\mathrm{b}}$ \\
\hline \multicolumn{6}{|l|}{ Etiology (HCV:HBV:HBV\&HCV: } \\
\hline NBNC:unknown) & $901: 150: 20: 230: 5$ & $208: 33: 2: 51: 2$ & $291: 45: 9: 88: 1$ & 402:72:9:91:2 & $0.426^{c}$ \\
\hline Total-bilirubin, $\mathrm{mg} / \mathrm{dL}^{\mathrm{a}}$ & $0.87(0.38)$ & $0.91(0.37)$ & $0.89(0.39)$ & $0.89(0.39)$ & $0.639^{\mathrm{b}}$ \\
\hline Albumin, $\mathrm{g} / \mathrm{dL}^{\mathrm{a}}$ & $3.77(0.42)$ & $3.78(0.39)$ & $3.77(0.42)$ & $3.76(0.42)$ & $0.768^{\mathrm{b}}$ \\
\hline Prothrombin time, $\%^{\mathrm{a}}$ & $86.3(12.9)$ & $85.8(12.5)$ & $86.1(13.3)$ & $86.7(12.8)$ & $0.607^{b}$ \\
\hline Child-Pugh score (5:6) & $801: 505$ & 179:117 & $262: 172$ & $360: 216$ & $0.743^{c}$ \\
\hline Maximum tumor size, $\mathrm{cm}^{\mathrm{a}}$ & $4.75(3.77)$ & $3.84(4.05)$ & $4.86(3.79)$ & $5.13(3.52)$ & $<0.001^{\mathrm{b}}$ \\
\hline Up-to-7 criteria (within:beyond) & 418:888 & $129: 167$ & $130: 304$ & 159:417 & $0.002^{\mathrm{c}}$ \\
\hline $\mathrm{AFP} \geq 100 \mathrm{ng} / \mathrm{mL}$ & $546(41.8 \%)$ & $0(0 \%)$ & $72(16.6 \%)$ & $474(82.3 \%)$ & $<0.001^{\mathrm{c}}$ \\
\hline AFP-L3 $\geq 10 \%$ & $528(40.4 \%)$ & $0(0 \%)$ & $64(14.7 \%)$ & $464(80.6 \%)$ & $<0.001^{\mathrm{c}}$ \\
\hline $\mathrm{DCP} \geq 100 \mathrm{mAU} / \mathrm{mL}$ & $787(60.3 \%)$ & $0(0 \%)$ & $298(68.7 \%)$ & 489 (84.9\%) & $<0.001^{\mathrm{c}}$ \\
\hline MST, years & 4.0 & 4.8 & 3.8 & 3.2 & $<0.001^{\mathrm{d}}$ \\
\hline
\end{tabular}

HCV, hepatitis C virus; HBV, hepatitis B virus; NBNC, negative for both HBV and HCV; AFP, alpha-fetoprotein; AFP-L3, fucosylated

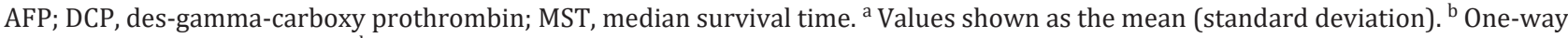
ANOVA. ${ }^{c}$ Kruskal-Wallis test. ${ }^{\mathrm{d}}$ log-rank test.

\section{Results}

The average age of the enrolled 1,306 patients was $69.4 \pm 9.0$ years old, and $77.1 \%$ were male $(n=1007)$. The median maximum tumor size was $4.0 \mathrm{~cm}$ (interquartile range [IQR]: 3.0-5.5). There were 888 patients classified as beyond up-to-7 criteria (68.0\%: BCLC subclass B2) and 249 (19.1\%) classified as TNM stage II (Table 1). Nine hundred and one were positive for HCV, 150 for HBV, and 20 for both HBV and HCV, while 230 were NBNC, and the etiology in 5 was undetermined. Median observation period was 1.4 years (IQR: 0.7-2.5). When tumor number was 6 or more, it was recorded as " 6 " in the present database. Four patients with small tumors ( $<1 \mathrm{~cm}$ in diameter) and with "6" tumors were categorized as within up-to-7 criteria in the present analysis.

Overall survival associated with each tumor marker score is shown in Figure 2a. A total of 390 died in the observation period. That was not different between patients with a score of 2 and those with a score of 3 ( $p=0.710$, Holm's method). Each factor of tumor marker score showed similar HR for prognosis (HR: AFP $\geq 100 \mathrm{ng} / \mathrm{mL}=1.708, \mathrm{~L} 310 \%=1.765$, and DCP $\geq 100 \mathrm{mAU} / \mathrm{mL}=1.700 ; p<0.001$, respectively). As a result, HR became larger with increasing score (HR: tumor marker score $1=1.552$, and $\geq 2=2.179 ; p<0.01$, respectively) (Table 2 ). Median survival time (MST) worsened with increasing tumor marker score (MST: tumor marker score $0=4.8$ years, $1=3.8$ years, $\geq 2=3.2$ years; $p<0.01$, Holm's method) (Fig. $2 \mathrm{~b}$ ). Regardless of tumor marker score, the prognosis of the patients within up-to-7 criteria was better than that of those beyond (Fig. 3).

Examinations of the prognostic factors for death with Cox hazard univariate analysis showed that the markers serum level of albumin $<3.5 \mathrm{~g} / \mathrm{dL}$ (HR 1.650, 95\% confidence interval [95\% CI] 1.321-2.062, $p<0.001$ ), tumor marker score $\geq 2$, Child-Pugh score 6 (HR 1.31, 95\% CI 1.202-1.428, $p<0.001$ ), and beyond up-to-7 criteria (subclass B2: HR 1.686, $95 \%$ CI 1.523-1.867, $p<0.001$ ) were significant. Furthermore, multivariate analysis also 


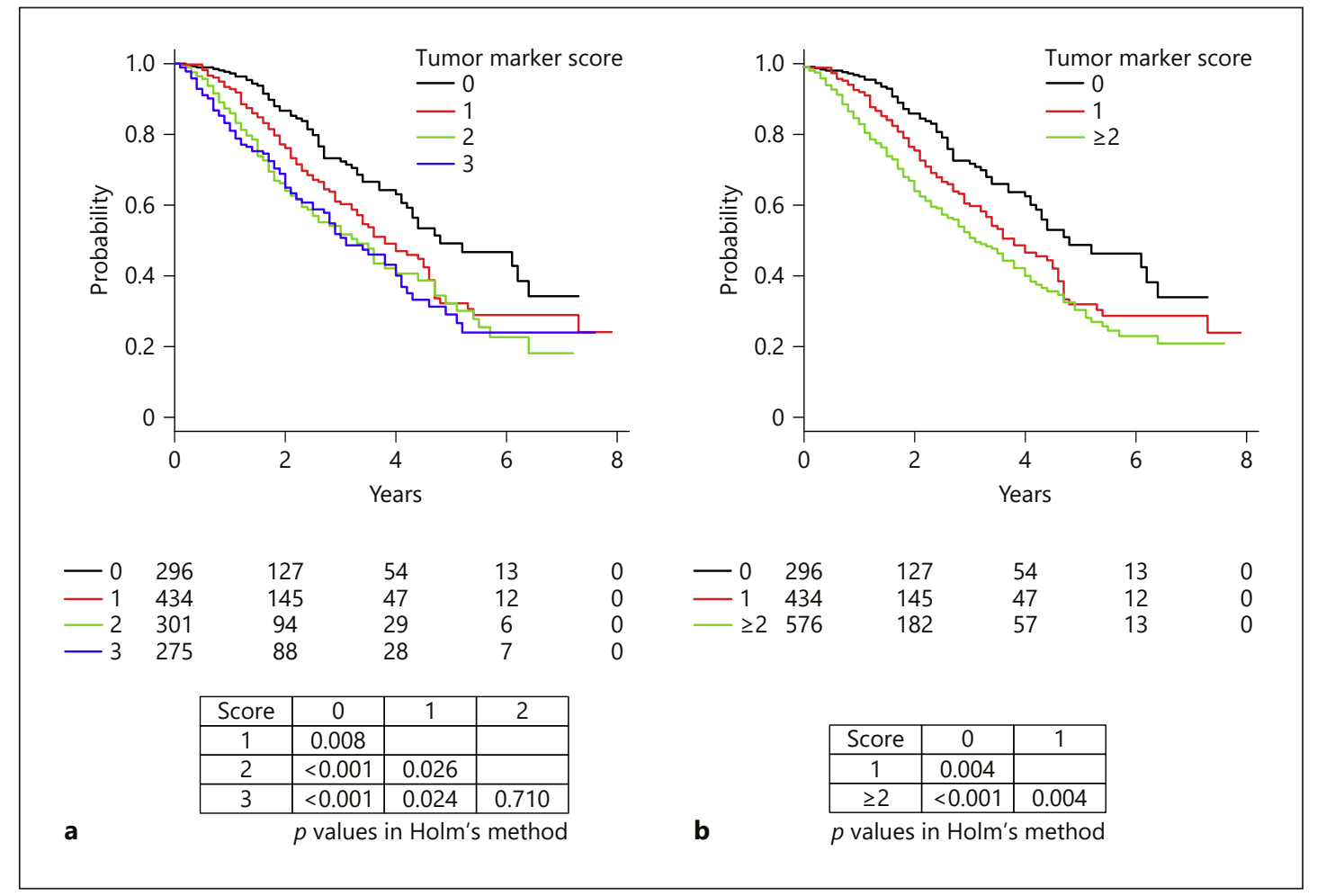

Fig. 2. Overall survival of intermediate-stage hepatocellular carcinoma patients (Child-Pugh A, multiple tumors) based on the tumor marker score. a Significant differences were observed among scores of 0,1 , and $2 / 3(p<0.05$, Holm's method), but not between scores of 2 and 3 ( $p=0.710$, Holm's method). b Median survival time both worsened as tumor marker score increased (tumor marker score $0=4.8$ years, $1=3.8$ years, $\geq 2=3.2$ years; $p<0.01$, Holm's method).

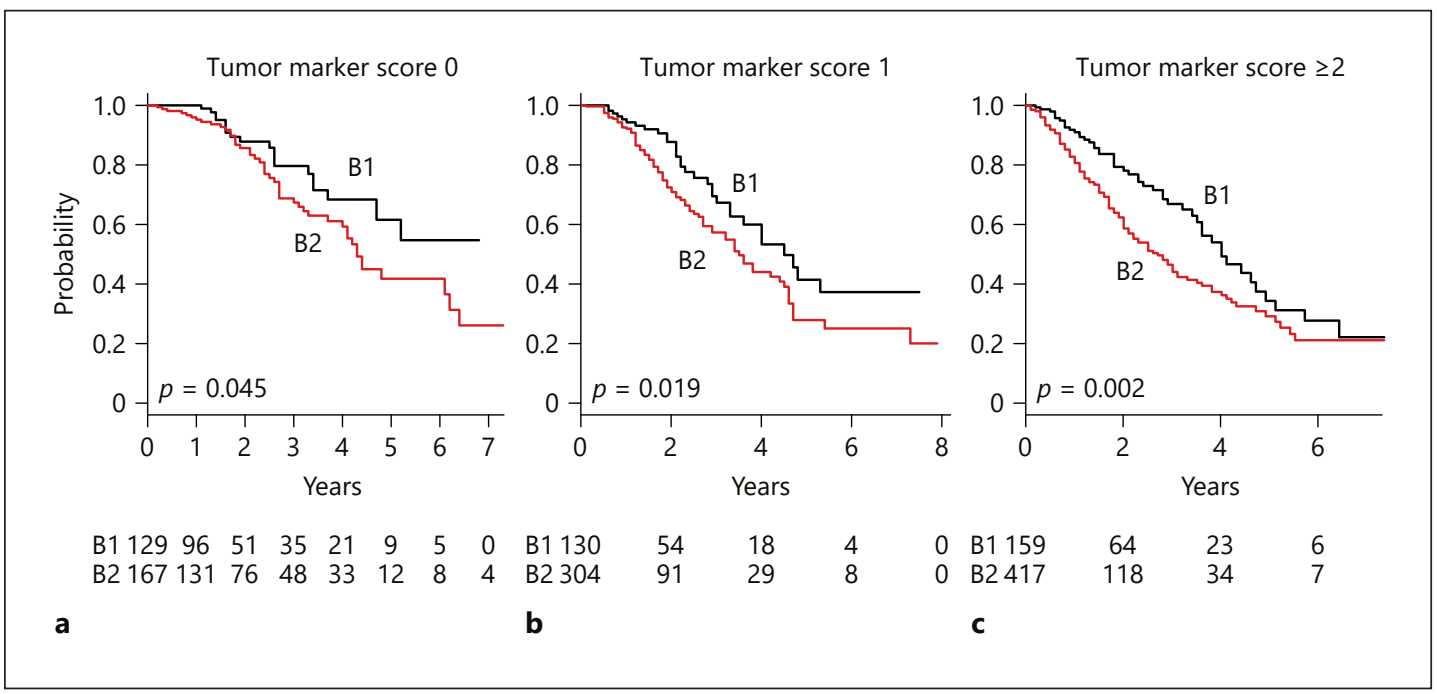

Fig. 3. Comparison between within and beyond up-to-7 criteria for each tumor marker score $(0,1, \geq 2)$. a Tumor marker score 0. Median survival time (MST) for those within up-to-7 criteria (B1) was better compared to that of those beyond (B2) (not available vs. 4.3 years, $p=0.045$ ). $\mathbf{b}$ Tumor marker score 1 . MST for B1 was better compared to that of B2 ( $4.5 \mathrm{vs.} 3.5$ years, $p=0.019$ ). c Tumor marker score $\geq 2$. MST for B1 was better compared to that of B2 ( 4.0 vs. 2.7 years, $p=0.002)$. 


\section{Liver Cancer}

Table 2. Prognostic factors for tumor marker score

\begin{tabular}{l|l}
\hline Liver Cancer 2019:8:403-411 \\
\hline DOI: 10.1159/000495944 & $\begin{array}{l}\text { @ 2019 S. Karger AG, Basel } \\
\text { www.karger.com/lic }\end{array}$ \\
\hline
\end{tabular}

\begin{tabular}{lllr}
\hline & HR & $95 \%$ CI & $p$ value \\
\hline AFP $\geq 100 \mathrm{ng} / \mathrm{mL}$ & 1.708 & $1.550-1.882$ & $<0.001$ \\
AFP-L3 $\geq 10 \%$ & 1.765 & $1.534-2.030$ & $<0.001$ \\
DCP $\geq 100 \mathrm{mAU} / \mathrm{mL}$ & 1.700 & $1.511-1.912$ & $<0.001$ \\
Tumor marker score & & & \\
$\quad 22$ & 2.179 & $1.649-2.879$ & $<0.001$ \\
1 & 1.552 & $1.151-2.094$ & 0.004 \\
0 & 1.0 & & \\
\hline
\end{tabular}

AFP, alpha-fetoprotein; AFP-L3, fucosylated AFP; DCP, des-gammacarboxy prothrombin.

Table 3. Clinical prognostic factors: Cox hazard analysis

\begin{tabular}{lllrlrr}
\hline & HR $^{\mathrm{a}}$ & \multicolumn{1}{l}{$95 \% \mathrm{CI}^{\mathrm{a}}$} & $p$ value $^{\mathrm{a}}$ & $\mathrm{HR}^{\mathrm{b}}$ & $95 \% \mathrm{CI}^{\mathrm{b}}$ & $p$ value $^{\mathrm{b}}$ \\
\hline Age $\geq 75$ years & 0.998 & $0.792-1.257$ & 0.985 & & & \\
HCV positive & 0.902 & $0.728-1.112$ & 0.344 & & & \\
Total bilirubin $\geq 2.0 \mathrm{mg} / \mathrm{dL}$ & 0.609 & $0.152-2.445$ & 0.484 & & & \\
Albumin $<3.5 \mathrm{~g} / \mathrm{dL}$ & 1.650 & $1.321-2.062$ & $<0.001$ & 1.377 & $1.003-1.894$ & 0.048 \\
PT $\geq 70 \%$ & 1.026 & $0.689-1.527$ & 0.901 & & & \\
Child-Pugh score 6 & 1.310 & $1.202-1.428$ & $<0.001$ & 1.247 & $0.935-1.662$ & 0.133 \\
Beyond up-to-7 criteria & 1.686 & $1.523-1.867$ & $<0.001$ & 1.728 & $1.375-2.172$ & $<0.001$ \\
Tumor marker score $\geq 2$ & 1.674 & $1.372-2.042$ & $<0.001$ & 1.675 & $1.372-2.044$ & $<0.001$ \\
\hline
\end{tabular}

HR, hazard ratio; 95\% CI, 95\% confidence interval; HCV, hepatitis C virus. ${ }^{a}$ Univariate analysis. ${ }^{\mathrm{b}}$ Multivariate analysis.

revealed tumor marker score ( $\geq 2$; HR 1.675, 95\% CI 1.372-2.044, $p<0.001)$, albumin $(<3.5$ g/dL; HR 1.377, 95\% CI 1.003-1.894, $p=0.048$ ), and up-to-7 criteria (HR 1.728, 95\% CI $1.375-2.172, p<0.001$ ) as significant factors for prognosis (Table 3 ).

\section{Discussion}

Recently, treatment with TKI, such as sorafenib [16-18] and regorafenib [19], has been given to patients with unresectable HCC and good reserve hepatic function, resulting in improved prognosis. Moreover, a new TKI, lenvatinib, has been recently reported [20, 21]. With the number of therapeutic options for patients with beyond BCLC-B HCC increasing [22], the importance of TACE-refractory status for deciding to switch therapy to improve prognosis has increased. Furthermore, a few studies have found that switching to sorafenib resulted in better prognosis for TACE-refractory patients as compared to those who were not switched [23, 24].

Although various reports have proposed predictive tools for prognosis of HCC patients treated repeatedly with TACE [25-27], the examined cohorts included a variety of conditions. Establishment of TACE-refractory status and strategies for switching treatment from TACE in BCLC-B HCC patients with good hepatic reserve function are needed. Studies performed in Western countries have provided some algorithms and scoring systems for judging TACErefractory status [4, 28]. In addition, criteria have been recently proposed in Japan [5], including "continuous elevation of tumor markers even though a transient minor reduction 


\section{Liver
Cancer}

\begin{tabular}{|c|c|}
\hline \multicolumn{2}{|l|}{ Liver Cancer 2019;8:403-411 } \\
\hline DOI: 10.1159/000495944 & $\begin{array}{l}\text { (c) } 2019 \text { S. Karger AG, Basel } \\
\text { www.karger.com/lic }\end{array}$ \\
\hline
\end{tabular}

Hiraoka et al.: Tumor Marker Score in Patients Undergoing TACE

is observed" for judging TACE-refractory patients. However, the majority of Asian experts ( $>80 \%$ ) mainly use imaging modalities for judging TACE-refractory patients [7]. The reasons could be the lack of cut-off values for TACE-refractory status in each tumor marker, and that discrepancies between imaging modality findings and tumor marker levels are often noted (e.g., stable disease shown by imaging modalities but no improvement of elevated tumor marker levels).

Kiriyama et al. [29] have reported on the influence of the expression pattern of the 3 tumor markers (AFP, AFP-L3, and DCP) on HCC malignancy and prognosis of HCC patients who underwent hepatectomy. Recently, a tumor marker scoring system that utilizes only these 3 tumor markers (AFP, AFP-L3, DCP) has been proposed as a simple prediction tool for prognosis of BCLC-B HCC patients treated repeatedly with TACE $[8,10]$. Because we should always keep in mind TACE-refractory status and switching to TKI treatments in TACErefractory patients when we start TACE treatment in the intermediate stage, we used the tumor markers at the time of introducing first TACE as the present score. In another report, tumor marker score was shown to be useful also for prediction of BCLC-B HCC prognosis after 2 TACE sessions [9]. The results of the present validation study were similar to those in previous reports. In addition, Toyoda et al. [30] found that simultaneous measurement of the 3 tumor markers to determine the number with positivity was useful for predicting tumor progression, outcome, and treatment efficacy.

The global investigation of therapeutic decisions in HCC and of its treatment with sorafenib (GIDEON) study, which was a prospective, global, noninterventional study, showed that the percentage of patients with Child-Pugh B at initiation of sorafenib was higher when the number of TACE sessions prior to sorafenib was 6 or more [31]. Another report found that repeated TACE for BCLC-B HCC resulted in a gradual worsening of hepatic reserve function [6]. In the present study, worse Child-Pugh score (score 6), in spite of Child-Pugh class A classification, was found to be an independent prognostic factor for poor prognosis. We consider that it is vital not to miss the opportunity of switching to TKI and to avoid hepatic reserve function worsening by appropriate judgment of TACE-refractory status.

Although therapeutic response shown by imaging modalities is recognized as stable disease, some cases that undergo repeated TACE have a sudden rapid progression. Recently, "Time To TACE Progression (TTTP)" [32, 33], which can predict future poor response based on slight volume change shown in imaging modalities, such as enhanced computed tomography and magnetic resonance imaging, has been reported. The combination of tumor marker score at the start of a repeated TACE course and shorter TTTP during the clinical course makes it easy to appropriately judge TACE-refractory status. Ogasawara et al. [34] reported that therapeutic efficacy is expected in patients who switch to sorafenib therapy prior to progression to an advanced-stage than in those who switch after that progression. Needless to say, to prolong the prognosis of BCLC-B HCC patients, adequately judging TACE-refractory status before progression to advanced stage is important, especially in patients who are expected to have poor prognosis.

Our study has some limitations. First, even though the cohort was large, it was conducted in a retrospective manner. Especially, the number of patients with missing data on AFP-L3 was large. Second, some detailed information regarding treatments after initial TACE is missing because data were obtained from a nationwide database. A prospective study will be needed to confirm the usefulness of this tumor marker score for BCLC-B HCC patients with good hepatic reserve function (Child-Pugh A). In addition, though TACE is recommended as the initial treatment for BCLC-B HCC, good therapeutic efficacy following resection [35] and radiofrequency ablation (RFA) [36] have been reported in some BCLC-B HCC cases. Curative treatments such as resection and RFA in selected patients may have the potential to improve prognosis as compared with TACE. Especially in the patients within up-to-7 criteria with good 
hepatic function, the efficacy of curative treatments and that of TACE should be compared in the near future.

In conclusion, our findings indicate that the proposed tumor marker score composed of only 3 tumor markers, i.e. AFP $\geq 100 \mathrm{ng} / \mathrm{mL}$, AFP-L3 $\geq 10 \%$, and DCP $\geq 100 \mathrm{mAU} / \mathrm{mL}$, is easy and useful for predicting the prognosis of BCLC-B HCC patients after introduction of TACE.

\section{Statement of Ethics}

Informed consent was obtained from all patients before treatment, and this retrospective analysis was approved by the LCSGJ committee.

\section{Disclosure Statement}

The authors declare no conflicts of interest.

\section{References}

1 Llovet JM, Brú C, Bruix J. Prognosis of hepatocellular carcinoma: the BCLC staging classification. Semin Liver Dis. 1999;19(3):329-38.

2 Bolondi L, Burroughs A, Dufour JF, Galle PR, Mazzaferro V, Piscaglia F, et al. Heterogeneity of patients with intermediate (BCLC B) Hepatocellular Carcinoma: proposal for a subclassification to facilitate treatment decisions. Semin Liver Dis. 2012 Nov;32(4):348-59.

3 Forner A, Llovet JM, Bruix J. Hepatocellular carcinoma. Lancet. 2012 Mar;379(9822):1245-55.

4 Dufour JF, Bargellini I, De Maria N, De Simone P, Goulis I, Marinho RT. Intermediate hepatocellular carcinoma: current treatments and future perspectives. Ann Oncol. 2013 Apr;24 Suppl 2:ii24-9.

5 Kudo M, Matsui O, Izumi N, Iijima H, Kadoya M, Imai Y, et al.; Liver Cancer Study Group of Japan. JSH ConsensusBased Clinical Practice Guidelines for the Management of Hepatocellular Carcinoma: 2014 Update by the Liver Cancer Study Group of Japan. Liver Cancer. 2014 Oct;3(3-4):458-68.

6 Hiraoka A, Kumada T, Kudo M, Hirooka M, Koizumi Y, Hiasa Y, et al.; Real-life Practice Experts for HCC (RELPEC) Study Group and HCC 48 Group (hepatocellular carcinoma experts from 48 clinics). Hepatic Function during Repeated TACE Procedures and Prognosis after Introducing Sorafenib in Patients with Unresectable Hepatocellular Carcinoma: multicenter Analysis. Dig Dis. 2017;35(6):602-10.

7 Kudo M, Matsui O, Izumi N, Kadoya M, Okusaka T, Miyayama S, et al.; Liver Cancer Study Group of Japan. Transarterial chemoembolization failure/refractoriness: JSH-LCSGJ criteria 2014 update. Oncology. 2014;87 Suppl 1:22-31.

8 Hiraoka A, Shimizu Y, Shiraishi A, Imai Y, Utsunomiya D, Tatsukawa H, et al. Simple method for predicting prognosis following transcatheter arterial chemo-embolization for switching to next therapy for advanced hepatocellular carcinoma without venous invasion or metastasis [Abstract in English]. Kanzo 2013 Jan;54(2): 161-163.

9 Hiraoka A, Ishimaru Y, Kawasaki H, Aibiki T, Okudaira T, Toshimori A, et al. Tumor Markers AFP, AFP-L3, and DCP in Hepatocellular Carcinoma Refractory to Transcatheter Arterial Chemoembolization. Oncology. 2015; 89(3):167-74.

10 Hiraoka A, Kumada T, Nouso K, Tsuji K, Itobayashi E, Hirooka M, et al. Simple methd with tumor markers for predicting prognosis following transcatheter arterial chemo-embolization for switching to next therapy in intermediate hepatocellular carcinoma: multi-center analysis [Abstract in English]. Kanzo. 2017;58(6):32937.

11 Liver Cancer Study Group of Japan. The general rules for the clinical and pathological study of primary liver cancer. 6th ed. Tokyo: Kanehara; 2015. p. 26.

12 Kudo M, Arizumi T, Ueshima K, Sakurai T, Kitano M, Nishida N. Subclassification of BCLC B Stage Hepatocellular Carcinoma and Treatment Strategies: Proposal of Modified Bolondi's Subclassification (Kinki Criteria). Dig Dis. 2015 Oct;33(6):751-8.

13 Mazzaferro V, Regalia E, Doci R, Andreola S, Pulvirenti A, Bozzetti F, et al. Liver transplantation for the treatment of small hepatocellular carcinomas in patients with cirrhosis. N Engl J Med. 1996 Mar;334(11): 693-9.

14 Mazzaferro V, Llovet JM, Miceli R, Bhoori S, Schiavo M, Mariani L, et al.; Metroticket Investigator Study Group. Predicting survival after liver transplantation in patients with hepatocellular carcinoma beyond the Milan criteria: a retrospective, exploratory analysis. Lancet Oncol. 2009 Jan;10(1):35-43. 
Hiraoka et al.: Tumor Marker Score in Patients Undergoing TACE

15 Kanda Y. Investigation of the freely available easy-to-use software 'EZR' for medical statistics. Bone Marrow Transplant. 2013 Mar;48(3):452-8.

16 Llovet JM, Ricci S, Mazzaferro V, Hilgard P, Gane E, Blanc JF, et al.; SHARP Investigators Study Group. Sorafenib in advanced hepatocellular carcinoma. N Engl J Med. 2008 Jul;359(4):378-90.

17 Cheng AL, Kang YK, Chen Z, Tsao CJ, Qin S, Kim JS, et al. Efficacy and safety of sorafenib in patients in the AsiaPacific region with advanced hepatocellular carcinoma: a phase III randomised, double-blind, placebocontrolled trial. Lancet Oncol. 2009 Jan;10(1):25-34.

18 Tanaka K, Shimada M, Kudo M. Characteristics of long-term survivors following sorafenib treatment for advanced hepatocellular carcinoma: report of a workshop at the 50th Annual Meeting of the Liver Cancer Study Group of Japan. Oncology. 2014;87(s1 Suppl 1):104-9.

19 Bruix J, Qin S, Merle P, Granito A, Huang YH, Bodoky G, et al.; RESORCE Investigators. Regorafenib for patients with hepatocellular carcinoma who progressed on sorafenib treatment (RESORCE): a randomised, doubleblind, placebo-controlled, phase 3 trial. Lancet. 2017 Jan;389(10064):56-66.

20 Ikeda K, Kudo M, Kawazoe S, Osaki Y, Ikeda M, Okusaka T, et al. Phase 2 study of lenvatinib in patients with advanced hepatocellular carcinoma. J Gastroenterol. 2017 Apr;52(4):512-9.

21 Cheng A, Finn RS, Qin S, KH, Han K, Ikeda K, et al. Phase III trial of lenvatinib (LEN) vs sorafenib (SOR) in firstline treatment of patients (pts) with unresectable hepatocellular carcinoma (uHCC). J Clin Oncol 2017 May; 35:abstr 4001.

22 Kudo M. A New Era of Systemic Therapy for Hepatocellular Carcinoma with Regorafenib and Lenvatinib. Liver Cancer. 2017 Jun;6(3):177-84.

23 Ogasawara S, Chiba T, Ooka Y, Kanogawa N, Motoyama T, Suzuki E, et al. Efficacy of sorafenib in intermediatestage hepatocellular carcinoma patients refractory to transarterial chemoembolization. Oncology. 2014; 87(6):330-41.

24 Arizumi T, Ueshima K, Minami T, Kono M, Chishina H, Takita M, et al. Effectiveness of Sorafenib in Patients with Transcatheter Arterial Chemoembolization (TACE) Refractory and Intermediate-Stage Hepatocellular Carcinoma. Liver Cancer. 2015 Dec;4(4):253-62.

25 Hiraoka A, Horiike N, Yamashita Y, Koizumi Y, Doi H, Yamamoto Y, et al. Risk factors for death in 224 cases of hepatocellular carcinoma after transcatheter arterial chemoembolization. Hepatogastroenterology. 2009 Jan-Feb;56(89):213-7.

26 Kadalayil L, Benini R, Pallan L, O’Beirne J, Marelli L, Yu D, et al. A simple prognostic scoring system for patients receiving transarterial embolisation for hepatocellular cancer. Ann Oncol. 2013 Oct;24(10):2565-70.

27 Ogasawara S, Chiba T, Ooka Y, Kanogawa N, Motoyama T, Suzuki E, et al. A prognostic score for patients with intermediate-stage hepatocellular carcinoma treated with transarterial chemoembolization. PLoS One. 2015 Apr;10(4):e0125244.

28 Hucke F, Sieghart W, Pinter M, Graziadei I, Vogel W, Müller C, et al. The ART-strategy: sequential assessment of the ART score predicts outcome of patients with hepatocellular carcinoma re-treated with TACE. J Hepatol. 2014 Jan;60(1):118-26.

29 Kiriyama S, Uchiyama K, Ueno M, Ozawa S, Hayami S, Tani M, et al. Triple positive tumor markers for hepatocellular carcinoma are useful predictors of poor survival. Ann Surg. 2011 Dec;254(6):984-91.

30 Toyoda H, Kumada T, Kiriyama S, Sone Y, Tanikawa M, Hisanaga Y, et al. Prognostic significance of simultaneous measurement of three tumor markers in patients with hepatocellular carcinoma. Clin Gastroenterol Hepatol. 2006 Jan;4(1):111-7.

31 Kudo M, Ikeda M, Takayama T, Numata K, Izumi N, Furuse J, et al. Safety and efficacy of sorafenib in Japanese patients with hepatocellular carcinoma in clinical practice: a subgroup analysis of GIDEON. J Gastroenterol. 2016 Dec;51(12):1150-60.

32 Arizumi T, Ueshima K, Iwanishi M, Minami T, Chishina H, Kono M, et al. The Overall Survival of Patients with Hepatocellular Carcinoma Correlates with the Newly Defined Time to Progression after Transarterial Chemoembolization. Liver Cancer. 2017 Jun;6(3):227-35.

33 Izumoto H, Hiraoka A, Ishimaru Y, Murakami T, Kitahata S, Ueki H, et al. Validation of Newly Proposed Time to Transarterial Chemoembolization Progression in Intermediate-Stage Hepatocellular Carcinoma Cases. Oncology. 2017;93 Suppl 1:120-6.

34 Ogasawara S, Chiba T, Ooka Y, Suzuki E, Inoue M, Wakamatsu T, et al. Analysis of Sorafenib Outcome: Focusing on the Clinical Course in Patients with Hepatocellular Carcinoma. PLoS One. 2016 Aug;11(8):e0161303.

35 Tada T, Kumada T, Toyoda H, Tsuji K, Hiraoka A, Itobayashi E, et al. Role of hepatic resection in patients with intermediate-stage hepatocellular carcinoma: A multicenter study from Japan. Cancer Sci. 2017 Jul;108(7): 1414-20.; epub ahead of print.

36 Hirooka M, Hiraoka A, Ochi H, Kisaka Y, Joko K, Michitaka K, et al. Transcatheter Arterial Chemoembolization With or Without Radiofrequency Ablation: Outcomes in Patients With Barcelona Clinic Liver Cancer Stage B Hepatocellular Carcinoma. AJR Am J Roentgenol. 2018 Apr;210(4):891-898. 